\title{
Dysregulation of insulin receptor substrate 2 in $\beta$ cells and brain causes obesity and diabetes
}

\author{
Xueying Lin, Akiko Taguchi, Sunmin Park, Jake A. Kushner, Fan Li, Yedan Li, and Morris F. White \\ Howard Hughes Medical Institute Children's Hospital, Division of Endocrinology, Harvard Medical School, Boston, Massachusetts, USA.
}

\begin{abstract}
The molecular link between obesity and $\beta$ cell failure that causes diabetes is difficult to establish. Here we show that a conditional knockout of insulin receptor substrate 2 (Irs2) in mouse pancreas $\beta$ cells and parts of the brain - including the hypothalamus -increased appetite, lean and fat body mass, linear growth, and insulin resistance that progressed to diabetes. Diabetes resolved when the mice were between 6 and 10 months of age: functional $\beta$ cells expressing Irs 2 repopulated the pancreas, restoring sufficient $\beta$ cell function to compensate for insulin resistance in the obese mice. Thus, Irs 2 signaling promotes regeneration of adult $\beta$ cells and central control of nutrient homeostasis, which can prevent obesity and diabetes in mice.
\end{abstract}

\section{Introduction}

Type 2 diabetes affects 18.2 million people in the United States and is increasingly common among young people $(1,2)$. Most disease models point to obesity as an important cause of type 2 diabetes, because of its association with skeletal muscle insulin resistance and pancreatic $\beta$ cell failure $(3,4)$. However, dysregulated peripheral and central signaling - owing to many different causes - might initiate and sustain the cascade of events that progress to obesity and diabetes. Most if not all insulin signals are produced or modulated through tyrosine phosphorylation of insulin receptor substrate 1 (IRS1); IRS2 or its homologs; or other scaffold proteins including Src-homology-2 (SH2) domains including SH2 domain containing Shc, Casitas B-lineage lymphoma proto-oncogene (c-CBL), adapter protein with a $\mathrm{PH}$ and $\mathrm{SH} 2$ domain (APS) and $\mathrm{SH} 2$ and $\mathrm{PH}$ domain containing signaling mediator 1 (SH2B), Grb-2 associated binder-I (GAB1), GAB2, or dreadlocks (DOCK, an SH3-SH2 adaptor protein) isoforms (5). Although the role of each of these substrates merits attention, cell-based experiments and work with transgenic mice suggest that many insulin responses are directly integrated with counterregulatory hormones and proinflammatory cytokines through tyrosine and serine phosphorylation of IRS1 and IRS2 (5). Dysregulation of these IRS proteins by proinflammatory cytokines or genetic deletion impairs glucose tolerance as a result of peripheral insulin resistance; however, systemic Irs $2^{-1-}$ mice also develop lifethreatening diabetes at 2-3 months of age because Irs 2 is required for $\beta$ cell growth, function, and survival (6-9). The progression of Irs $2^{-/-}$mice toward diabetes is retarded or prevented by modifying elements of the insulin/IGF-signaling cascade that promote compensatory $\beta$ cell function - including downregulation of protein tyrosine phosphatase Ptp1b or the transcription factor Foxo1; or upregulation of Akt (also called protein kinase $\mathrm{B}$, or $\mathrm{PKB}$ ) or pancreatic duodenal homeobox 1 (Pdx1) (9-14). Transgenic upregulation of Irs 2 in pancreatic $\beta$ cells also prevents diabetes in Irs $2^{-/-}$mice,

Nonstandard abbreviations used: $c r^{2}$, TgN[Ins2Cre]25Mgn; fIrs2, floxed Irs2; GLP1, glucagon-like peptide 1; Irs, insulin receptor substrate; Mc4r, melanocortin 4 receptor; $\alpha \mathrm{MSH}, \alpha$ melanocyte-stimulating hormone; Pdx1, pancreatic duodenal homeobox 1; Pomc, pro-opiomelanocortin; Stat3, signal transducer and activator of transcription 3. Conflict of interest: The authors have declared that no conflict of interest exists.

Citation for this article: J. Clin. Invest. 114:908-916 (2004).

doi:10.1172/JCI200422217. obese mice, and streptozotocin-induced diabetic mice by promoting sufficient and sustained compensatory insulin secretion (9). Thus, the Irs 2 branch of the insulin/IGF-signaling cascade is a common link between peripheral insulin action and secretion.

A molecular basis for the close association between obesity and peripheral insulin resistance is difficult to establish. Dysregulated signaling - rather than antidotal consumption of high-calorie diets - might contribute to the early development of obesity that progresses to diabetes (15-17). Insulin, leptin, and adiponectin are important peripheral signals that inform the brain of shortand long-term nutrient availability (17-19). Pharmacologic inhibition of insulin signaling in the hypothalamus increases food intake, and conditional $\mathrm{KO}$ of the insulin receptor in the brain causes obesity in mice on high-fat diets (20-23). Leptin secreted from adipocytes promotes satiety and energy utilization, at least in part by promoting $\alpha$ melanocyte-stimulating hormone ( $\alpha \mathrm{MSH})$ production in the hypothalamus (15). Mutations that disrupt neuronal leptin signaling or melanocortin signaling increase food intake, body weight, and peripheral insulin resistance in mice and people that progresses to diabetes if $\beta$ cell function also deteriorates (24-26). Adiponectin, another adipocyte-derived hormone, enhances hepatic and muscle insulin action and promotes energy expenditure through signaling in the hypothalamus $(18,27)$; however, adiponectin is reduced in obese people and rodents $(28,29)$.

Previous work suggests that Irs2 signaling plays an important role in the CNS for brain growth, female fertility, and nutrient homeostasis (30). Since IRS2 is highly expressed in the hypothalamus, its signaling cascade may be responsible for integrating central control of nutrient homeostasis and appetite regulation with peripheral insulin action and $\beta$ cell function (9). Female Irs $2^{-/-}$mice - which develop diabetes more slowly than do male mice - are hyperphagic and obese until severe diabetes causes weight loss (30). To test the role of selective Irs2 dysregulation in obesity and diabetes, we flanked the Irs 2 gene with loxP recombination sites (floxed Irs2, or fIrs2) and crossed these mice with transgenic mice expressing Cre recombinase under control of the rat insulin-2 promoter (TgN[Ins2Cre]25Mgn mice, or $c r^{2}$ mice). Cre recombinase is expressed strongly in $\beta$ cells and weakly in certain brain regions of these transgenic $c r^{2}$ mice $(31,32)$. Thus, our strategy strongly deleted fIrs 2 alleles from $\beta$ cells and weakly deleted them from brain and 


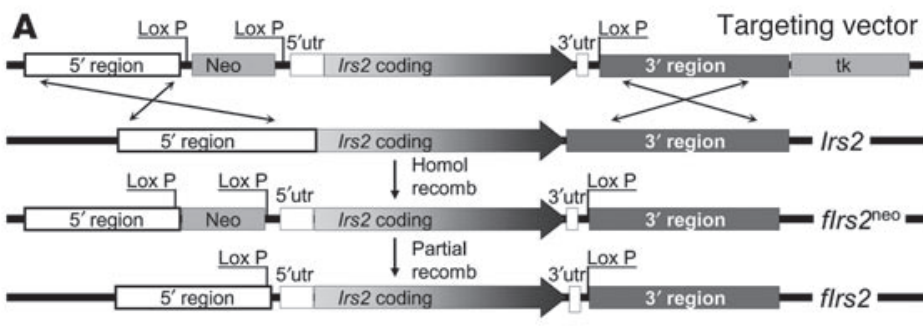

B

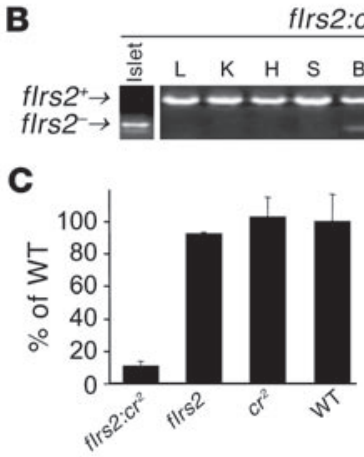

Irs2: $\mathrm{Cr}^{2}$

flrs2

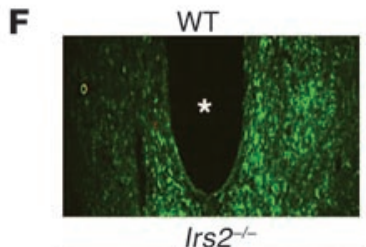

Irs2-

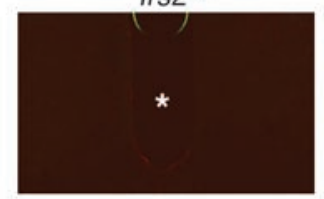

D flrs2:cr² flrs2

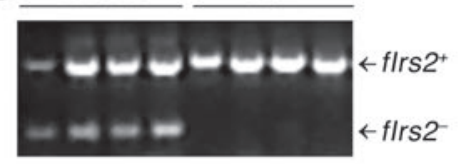

E
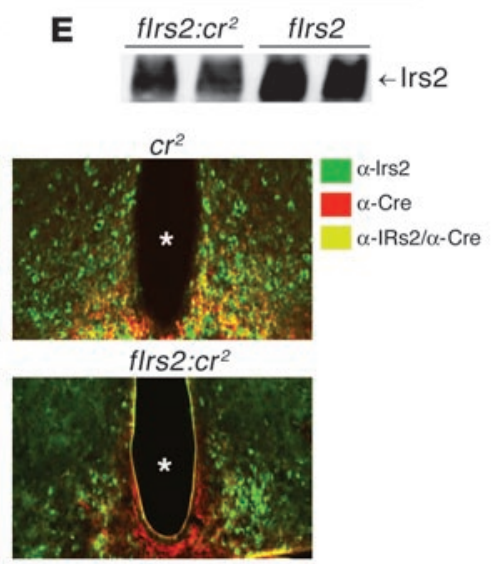

certain neurons of the hypothalamus. Analysis of the mice suggests that dysregulated Irs 2 signaling could be a common link between obesity and $\beta$ cell failure that progresses to diabetes; and that Irs2 signaling is an important element for $\beta$ cell regeneration.

\section{Results}

Conditional disruption of floxed Irs 2 allele by $\mathrm{cr}^{2}$. To determine whether partial dysregulation of Irs 2 signaling links obesity and diabetes, we intercrossed mice containing homozygous fIrs 2 alleles with $c r^{2}$ mice (Figure 1A). PCR analysis of islets from the compound fIrs2: $c r^{2}$ mice (4 weeks old) confirmed that fIrs 2 alleles were almost completely deleted, which was consistent with the reported efficacy of $c r^{2}$ in $\beta$ cells (Figure 1B). Since islets are composed mainly of $\beta$ cells, Irs 2 mRNA levels decreased at least 90\% (Figure 1C). fIrs 2 alleles were partially deleted in the brain, including regions of the hypothalamus (Figure 1, B and D), which is consistent with the reported expression of $\mathrm{cr}^{2}$ in some neurons $(31,32)$. At 8 weeks, Irs2 protein levels were reduced at least $30 \%$ in fIrs2: $c r^{2}$ hypothalamic extracts (Figure 1E). By contrast, fIrs 2 was intact and protein levels were normal in other tested tissues, including muscle, liver, and fat (Figure $1 \mathrm{~B}$ and data not shown).

To verify that fIrs 2 was disrupted in hypothalamic neurons, we immunostained sections of the arcuate nucleus with antibodies against Irs2 (green stain) and Cre recombinase (red stain); low background was confirmed in systemic Irs $2^{-/-}$brain sections that

\section{Figure 1}

Creation of flrs 2 mice and $c r^{2}$-mediated recombination/deletion of flrs2. (A) A schematic diagram of the 4 steps in the generation of the flrs2 containing embryonic stem cells (see Methods for details). Homol recomb, homologous recombination. (B) Recombination/deletion of flrs2 was revealed in various mouse tissues at 4 weeks of age by PCR analysis of genomic DNA. L, liver; K, kidney; $\mathrm{H}$, heart; S, spleen; B, brain, F, fat; M, muscle. The intact flrs2 allele (fIrs2 ${ }^{+}$) yields a 750 -bp fragment, whereas the recombined/deleted allele (fIrs2-) yields a 250-bp fragment. (C) Realtime PCR analysis of Irs2 expression in isolated islets, normalized by cyclophilin expression. (D) PCR analysis of hypothalamic DNA to reveal recombination event. (E) Immunoprecipitation and Western blot analysis of hypothalamus with antibodies against Irs2. (F) Brain sections were immunostained with antibodies against Irs2 (red) and Cre (green), and the images were merged in Openlab Image software (version 3.14; Improvision). Similar results were obtained with multiple sections from 2 to 8 mice. Asterisks indicate third ventricle. Magnification, $\times 20$.

lack both proteins (Figure $1 F$ ). Irs2 was detected in the arcuate nucleus from WT or $c r^{2}$ mice, and Cre recombinase was detected in $c r^{2}$ mice, where it was expressed in some (yellow staining) but not all Irs2-positive neurons (Figure 1F). However, coexpression of Irs 2 and Cre was largely abolished in fIrs2: $c r^{2}$ sections, which confirmed that fIrs2 was deleted wherever Cre was expressed (Figure 1F); similar results were found in paraventricular nucleus (data not shown).

Growth of the fIrs2: $c r^{2}$ mice. The fIrs $2: c r^{2}$ mice reached a normal body weight at 4 weeks of age but then grew more rapidly and were $30 \%$ heavier than controls when the experiment was terminated at 32 weeks (Figure 2A). At 8 weeks, flrs $2: c r^{2}$ mice were 8 grams heavier than the controls (fIrs $2: \mathrm{cr}^{2}, 38.2 \pm 0.6 \mathrm{~g}$, $P<0.01$ compared with fIrs $2,29.8 \pm 0.5 \mathrm{~g} ; \mathrm{cr}^{2}, 29.4 \pm 0.8 \mathrm{~g}$; and WT, $29.1 \pm 0.6 \mathrm{~g})$; and they consumed 60\% $(P<0.05)$ more chow (9\% fat) and $65 \%(P=0.001)$ more water than did the control mice during a 24-hour interval (Figure 2, B and C). Unlike systemic Irs $2^{-/-}$mice, which have small brains (33), the fIrs $2: \mathrm{cr}^{2}$ mice had a normal brain size (fIrs $2: c r^{2}, 0.41 \pm 0.01 \mathrm{~g} ;$ fIrs $2,0.40 \pm 0.01 \mathrm{~g} ; \mathrm{cr}^{2}$, $0.40 \pm 0.02 \mathrm{~g}$; and WT, $0.40 \pm 0.02 \mathrm{~g}$ ).

The fIrs $2: \mathrm{cr}^{2}$ mice were $10 \%$ longer - snout to anus - than the controls (fIrs2: $\mathrm{cr}^{2}, 107.9 \pm 0.5 \mathrm{~mm}, P<0.01$ compared with fIrs $2,98 \pm 2$ $\mathrm{mm} ; \mathrm{cr}^{2}, 96.5 \pm 0.4 \mathrm{~mm}$; WT, $\left.98 \pm 1 \mathrm{~mm}\right)$. On the normal $9 \%$ fat diet, 8-week-old fIrs 2: $\mathrm{Cr}^{2}$ mice had 2-fold more body fat and increased lean body mass (Figure 2D). Chemical analysis confirmed that fat mass was increased disproportionately in fIrs2:cr mice (fIrs $2: c r^{2}$, $18 \% \pm 3 \%$ fat, $n=5$; fIrs $2,11 \% \pm 1 \%$ fat,$n=4 ; P=0.005)$. Consistent with the increased adiposity, serum leptin and insulin levels were elevated 2-fold in the fIrs2: $\mathrm{Cr}^{2}$ mice compared with controls (Figure $2 \mathrm{E})$. Because of their larger size, fIrs $2: \mathrm{cr}^{2}$ mice produced more heat than control mice during a 24-hour period (fIrs2:cr², $14.1 \pm 0.1 \mathrm{kcal}$; WT, $11.0 \pm 1.5 \mathrm{kcal}$ ). Although caloric restriction achieved by feeding the mice a low-fat (5\%) diet reduced the weight of all the mice, the flrs2: $\mathrm{cr}{ }^{2}$ mice were consistently heavier (Figure 2A).

Glucose homeostasis in the fIrs 2: $\mathrm{Cr}^{2}$ mice. Diabetes developed in the fIrs 2: $c r^{2}$ mice between 8 and 10 weeks of age, as fasting glucose levels exceeded those of the control mice (fIrs $2: \mathrm{cr}^{2}, 110 \pm 9 \mathrm{mg} / \mathrm{dl}, P<0.01$ compared with flrs $2,63 \pm 2 \mathrm{mg} / \mathrm{dl} ; \mathrm{cr}^{2}, 60 \pm 4 \mathrm{mg} / \mathrm{dl}$; WT, $62 \pm 6 \mathrm{mg} /$ dl). Moreover, random-fed glucose was consistently 2 -fold higher in the fIrs 2: $\mathrm{cr}{ }^{2}$ mice than in the controls (Figure 2A). Glucose disposal rates measured in the fIrs $2: c r^{2}$ mice - during a hyperinsulinemic/ 


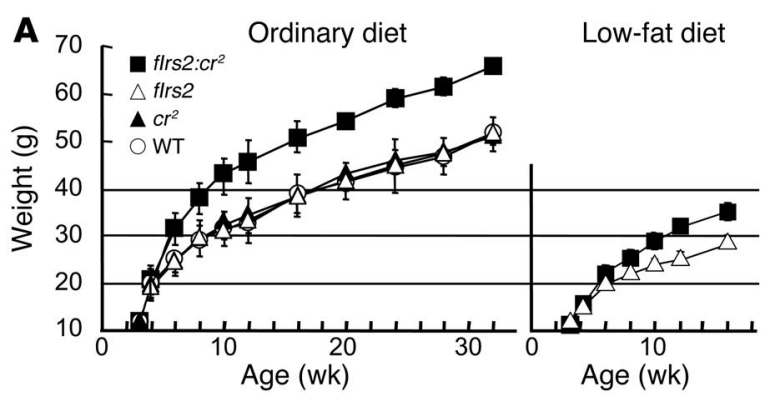

B

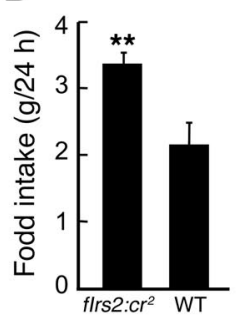

C

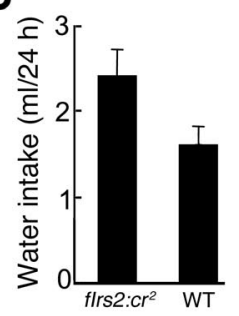

D

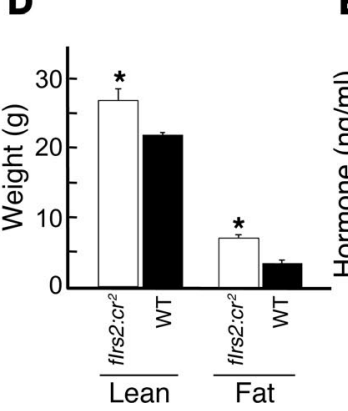

E

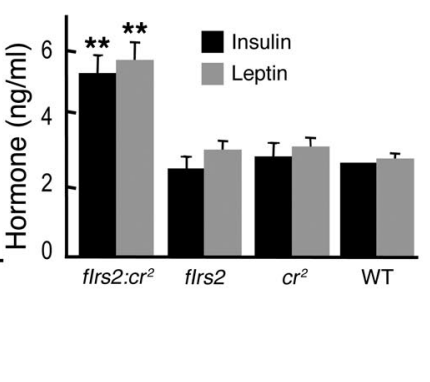

Figure 2

Growth and nutrient homeostasis of the fIrs2: $c r^{2}$ mice. (A) Male littermates fed regular or low-fat chow were weighed weekly from postnatal day 21 until 32 weeks of age; each point represents the average \pm SE of at least 6 mice. Omitted error bars are smaller than the symbol. (B) Food intake was determined with 8-weekold male mice over 24 hours using a Comprehensive Lab Animal Monitoring System; average \pm SE for 4 animals per genotype is reported. (C) Cumulative water intake was determined with 8-week-old male mice over 24 hours using a Comprehensive Lab Animal Monitoring System; average \pm SE for 3 animals per genotype is reported. (D) Average lean and fat body mass \pm SE was determined on three 8-week-old male of the indicated genotypes using a dual energy X-ray absorptiometry (DEXA) scanner (GE Medical Systems Lunar) according to the manufacturer's instructions. (E) Average \pm SE plasma insulin and leptin levels were determined on at least fifteen 8-week-old random fed male mice of each genotype using a rat insulin or mouse leptin ELISA Kit. ${ }^{\star} P<0.05 ;{ }^{\star \star} P<0.01$. euglycemic clamp test - were reduced 50\%, which revealed peripheral insulin resistance, an important hallmark of type 2 diabetes (Figure 2B). By contrast, hepatic glucose output measured before and during experimental hyperinsulinemia was similar in all of the mice examined (Figure 3C).

The insulin content of the fIrs $2: \mathrm{cr}^{2}$ pancreas was reduced more than 2-fold compared with that in the control mice (Figure 3D). This result is consistent with a positive role for IRS 2 in $\beta$ cell function, especially during compensation for peripheral insulin resistance (9). Intraperitoneal glucose injections following a 16-hour overnight fast confirmed glucose intolerance and diabetes in fIrs2: $c r^{2}$ mice (Figure 3E). Although glucose tolerance improved when the fIrs $2: c r^{2}$ mice were placed on the low-fat diet, fIrs $2: c r^{2}$ mice remained hyperinsulinemic (fIrs $2: \mathrm{cr}^{2}, 2.5 \pm 0.2 \mathrm{ng} / \mathrm{ml}, P<0.01$ compared with fIrs $2,0.7 \pm 0.1 \mathrm{ng} / \mathrm{ml} ; r^{2}, 0.6 \pm 0.1 \mathrm{ng} / \mathrm{ml}$; WT, $0.5 \pm 0.1 \mathrm{ng} / \mathrm{ml}$ ) and relatively glucose intolerant in comparison with control mice on the low-fat diet (Figure 3F).

\section{Figure 3}

Glucose homeostasis in the fIrs2: $\mathrm{cr}^{2}$ mice. (A) Average \pm SE randomfed blood glucose levels were determined using a Glucometer Elite in at least fifteen 8-week-old male mice of the indicated genotypes. (B and C) Glucose-disposal rates and hepatic glucose output before and during hyperinsulinemia (average \pm SE) were determined on 6-10 fasted and conscious 10-week-old male mice of the indicated genotypes. (D) Pancreas insulin content was determined using rat insulin ELISA Kit following acid-ethanol extraction. Results are average \pm SE for five 8-week-old mice per genotype. (E) After a 16-hour overnight fast, blood glucose (average \pm SE) was determined on at least fifteen 8-week-old male mice of the indicated genotypes following intraperitoneal injection of $2 \mathrm{~g} \mathrm{D}$-glucose/ $\mathrm{kg}$ body weight. (F) The integrated glucose tolerance (GTT, $\mathrm{t}=0 \rightarrow 120 \mathrm{~min}$ ) for the 8-week old male mice fed the ordinary diet (data in E) was compared with that for 16-week-old male mice fed a low-fat diet (LFD, 5\%); these ages were selected for comparison to match the body weights. The glucose tolerance curves were integrated using the trapezoid rule implemented in Sigmaplot 8.0 (Systat Software Inc.). ${ }^{*} P<0.05 ;{ }^{* \star} P<0.01$. $\beta$ cell growth and function in fIrs $2: \mathrm{cr}^{2}$ mice. The growth, function, and survival of $\beta$ cells are essential for normal glucose homeostasis, especially during compensation for peripheral insulin resistance. At 4 weeks of age when the fIrs $2: c r^{2}$ mice had a normal body weight, relative $\beta$ cell content - estimated by the average $\beta$ cell area in pancreas sections - and $\beta$ cell size were indistinguishable from those of control mice (Table 1). The expression of several genes that promote $\beta$ cell function and growth - hepatocyte nuclear factor $3 \beta$ (Hnf $3 \beta), H n f 4 \alpha$, and $P d x 1$ - were decreased in fIrs $2: c r^{2}$ islets; however, glucose transporter 2 (Glut2) mRNA levels were nearly normal
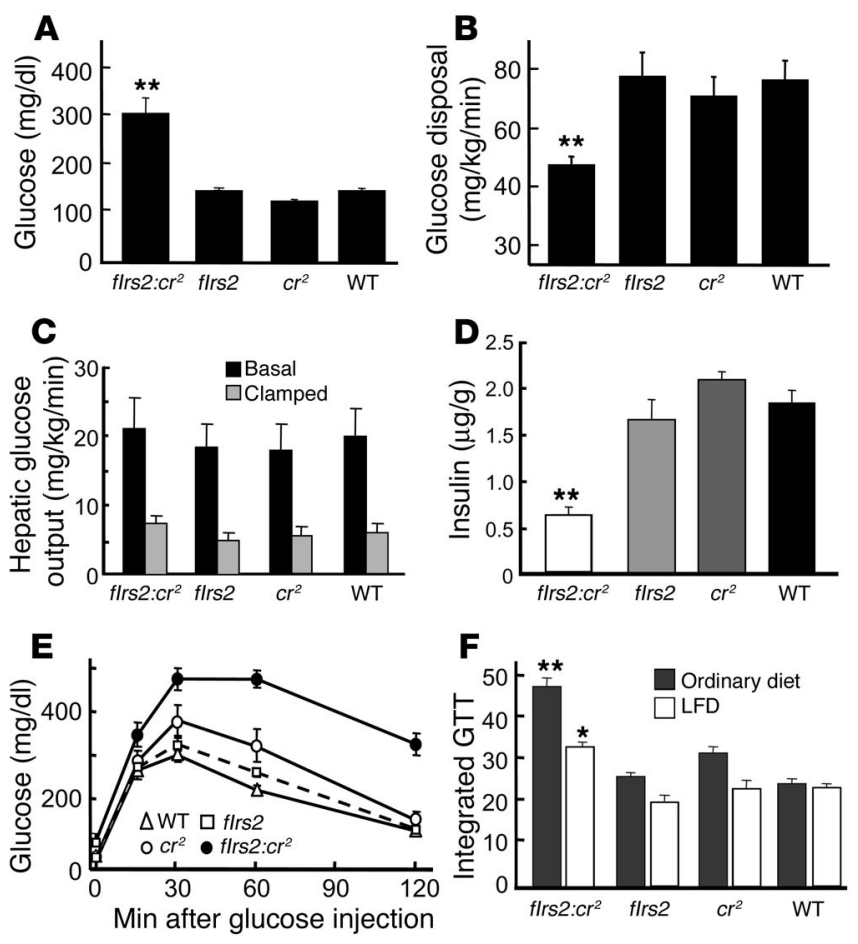
Table 1

Islet characteristics

\begin{tabular}{|c|c|c|c|c|c|c|}
\hline & flrs2:cr ${ }^{2}$ & flrs2:cr':Irs1+- & flrs2 & flrs2:Irs1+- & $c r^{2}$ & WT \\
\hline \multicolumn{7}{|l|}{4 weeks } \\
\hline$\beta$ Cell area & $0.5 \pm 0.1(4)$ & - & - & - & - & $0.5 \pm 0.1(5)$ \\
\hline$\beta$ Cell size & $77 \pm 8(4)$ & - & $75 \pm 6(6)$ & - & $86 \pm 10(3)$ & $78 \pm 7(5)$ \\
\hline BrdU (\%) & $2.0 \pm 0.4(4)$ & - & $1.5 \pm 0.2(6)$ & - & $1.1 \pm 0.2(3)$ & $1.6 \pm 0.3(5)$ \\
\hline \multicolumn{7}{|l|}{ Real-time PCR } \\
\hline$H n f 3 \beta(\%)$ & $41 \pm 7(4)^{\mathrm{A}}$ & - & $98 \pm 11(5)$ & - & $94 \pm 15(4)$ & $100 \pm 8(4)$ \\
\hline$P d \times 1(\%)$ & $46 \pm 4(4)^{B}$ & - & $103 \pm 9(5)$ & - & $107 \pm 1(4)$ & $100 \pm 7(4)$ \\
\hline$H n f 4 \alpha(\%)$ & $30 \pm 1(4)^{A}$ & - & $99 \pm 13(5)$ & - & $89 \pm 23(4)$ & $100 \pm 11(4)$ \\
\hline Glut2 (\%) & $69 \pm 12(4)$ & - & $93 \pm 10(5)$ & - & $97 \pm 15(4)$ & $100 \pm 8(4)$ \\
\hline \multicolumn{7}{|l|}{8 weeks } \\
\hline$\beta$ Cell area & $0.45 \pm 0.06(5)^{\mathrm{A}}$ & - & $0.94 \pm 0.08(6)$ & - & $0.9 \pm 0.1(4)$ & $0.88 \pm 0.07(5)$ \\
\hline \multicolumn{7}{|l|}{6 months } \\
\hline$\beta$ Cell area & $1.1 \pm 0.1(5)$ & $0.20 \pm 0.05(6)$ & - & $1.6 \pm 0.2(6)$ & - & $1.1 \pm 0.1(5)$ \\
\hline \multicolumn{7}{|l|}{10 months } \\
\hline$\beta$ Cell area (\% of total) & $3.4 \pm 0.1(5)$ & - & $3.5 \pm 0.6(4)$ & - & $3.7 \pm 0.1(4)$ & $3.3 \pm 0.5(4)$ \\
\hline$\beta$ Cell mass ( $\mu \mathrm{g} /$ pancreas) & $1,698 \pm 79(5)$ & - & $1414 \pm 246(4)$ & - & $1341 \pm 91(4)$ & $1,389 \pm 248(4)$ \\
\hline Islets/pancreas $(<10 \beta$ cells) & $52 \pm 9(4)^{A}$ & - & - & - & - & $30 \pm 6(3)$ \\
\hline Islets/pancreas ( $<10 \beta$ cells) & $25 \pm 6(4)^{A}$ & - & - & - & - & $22 \pm 3(3)$ \\
\hline Total islets/pancreas & $77 \pm 11$ & - & - & - & - & $52 \pm 7$ \\
\hline
\end{tabular}

Islet characteristics were calculated as previously described (9) and summarized briefly in Methods. The number of animals used for each genotype and the average \pm SE is reported. ${ }^{A} P<0.05 ;{ }^{B} P<0.01$. - , not determined.

(Table 1). DNA synthesis - estimated by in situ BrdU incorporation-was not significantly different in fIrs 2: $c r^{2}$ islets (Table 1). Nevertheless, $\beta$ cell content in the fIrs $2: \mathrm{cr}^{2}$ mice did not increase during the next 4 weeks, contrary to what was observed in 8-weekold control mice. These characteristics were consistent with the reduced insulin content of the fIrs2: $c r^{2}$ pancreas (Figure 3D).

Based upon our experience with systemic Irs $2^{-/-}$mice (9), we expected hyperglycemia to progress and eventually kill the fIrs 2:cr mice; however, diabetes always resolved spontaneously between 6 and 8 months of age (Figure 4A). At 6 months, relative $\beta$ cell content of fIrs $2: \mathrm{cr}^{2}$ mice was normal in comparison with WT mice; and by 10 months, the relative $\beta$ cell mass increased in all of the mice to compensate for peripheral insulin resistance that always emerges as the mice age and gain weight (Table 1). The nondiabetic fIrs $2: \mathrm{cr}^{2}$ mice remained heavier than the control mice (fIrs2:cr ${ }^{2}, 68 \pm 2 \mathrm{~g}$; fIrs 2, $51 \pm 2 \mathrm{~g} ; c r^{2}, 53 \pm 1 \mathrm{~g}$ ); and owing to a larger pancreas at 10 months, the total $\beta$ cell mass in fIrs 2:cr mice was slightly greater than that in controls (Table 1). At 10 months, pancreas sections from fIrs $2: \mathrm{cr}^{2}$ mice contained more islets, but a disproportionate number of the islet sections contained fewer than $10 \beta$ cells (Table 1 ). Thus, persistent insulin resistance was balanced by the growth of functional $\beta$ cells that maintained compensatory hyperinsulinemia in mice at 10 months of age (Figure 4B); and during the next year, these mice did not develop diabetes.

What reversed the progression to diabetes? We isolated individual islets from fIrs 2: $c r^{2}$ mice at 4, 6, and 10 months of age and used PCR to identify the presence or absence of the fIrs 2 allele. At 4 months, most islets lacked fIrs 2 , whereas a few islets displayed a mixture of deleted and intact fIrs 2 (Figure 4C). At 6 months, islets contained either deleted fIrs2, intact fIrs 2 , or a mixture of these alleles; and by 10 months, deleted fIrs 2 was never detected (Figure $4 \mathrm{C})$. Thus, fIrs $2^{-/} \beta$ cells were progressively replaced by $\beta$ cells containing fIrs 2 . The progressive decline of Cre recombinase in islets between 1 and 12 months of age suggests that regenerated $\beta$ cells arise from cells that weakly express Cre recombinase (Figure 4D); however, we cannot establish the source of these new $\beta$ cells.

The role of IRS1 in $\beta$ cell regeneration. Peripheral insulin action is mediated by both Irs 1 and Irs2 (5); however, systemic Irs $1^{-/-}$mice never develop diabetes, as Irs 2 promotes $\beta$ cell growth and function to compensate for peripheral insulin resistance (34). Previous work shows that Irs 1 haploinsufficiency strongly inhibits residual growth, function, and survival of $\beta$ cells in systemic Irs $2^{-/-}$mice, as $\beta$ cells are nearly undetected when systemic $\operatorname{Irs} 2^{-1-}: \operatorname{Ir} s 1^{+/-}$mice die at 30 days of age (34). To determine whether Irs 1 contributes to the regeneration of $\beta$ cells in fIrs $2: \mathrm{cr}^{2}$ mice, we intercrossed fIrs $2: \mathrm{cr}^{2}$ mice with systemic Irs $1^{+/-}$mice to produce compound [fIrs2:cr ${ }^{2}$ ]: Irs $1^{+/-}$mice. Unlike systemic Irs $1^{+/-}$mice or fIrs $2: \mathrm{cr}^{2}$ mice, the [fIrs2: $\mathrm{cr}^{2}$ ]:Irs $1^{+/-}$mice developed diabetes at 4 weeks (Figure 4A). The early-onset diabetes progressed rapidly to severe hyperglycemia as serum insulin levels fell during the next several months (Figure 4B). As a result of progressive and severe hypoinsulinemia, the [fIrs $\left.2: c r^{2}\right]: I r s 1^{+/-}$mice gained less weight than the fIrs2: $c r^{2}$ mice during the study period (Figure 4E). When the [fIrs2: $\left.c r^{2}\right]: I r s 1^{+/-}$mice were sacrificed at 6 months, relative $\beta$ cell content was reduced 8 -fold in comparison with the insulin-resistant but normal-sized Irs $1^{+/-}$mice (Figure 4F and Table 1 ). Although $\beta$ cells containing insulin were detected in the [fIrs $\left.2: c r^{2}\right]: I r s 1^{+/-}$pancreas at 6 months, the small islets were disproportionately populated by $\alpha$ cells (Figure $4 \mathrm{~F}$ ). The striking discrepancy between the $\beta$ cell mass of fIrs: $c r^{2}: I r s 1^{+/}$-mice compared with fIrs2: $c r^{2}$ mice was unexpected, as $\beta$ cells retaining fIrs 2 alleles should grow in both cases; unfortunately, it was impossible to isolate intact islets from 6 month old [fIrs2: $\left.c r^{2}\right]: \operatorname{Irs} 1^{+/-}$mice for genotyping.

Hypothalamic function in fIrs2:cr mice. The fIrs 2:cr ${ }^{2}$ mice closely resemble agouti mice or mice deficient in pro-opiomelanocortin $\left(\right.$ Pomc $\left.^{-/-}\right)$or melanocortin 4 receptor $\left({\left.\mathrm{Mc} 4 \mathrm{r}^{-/}\right)}^{-1}\right.$ (15), which suggests that Irs 2 mediates some effects of insulin upon the melanocortin pathway in the hypothalamus. To evaluate insulin signaling, we prepared hypothalamic extracts from WT or fIrs $2: c r^{2}$ mice 15 

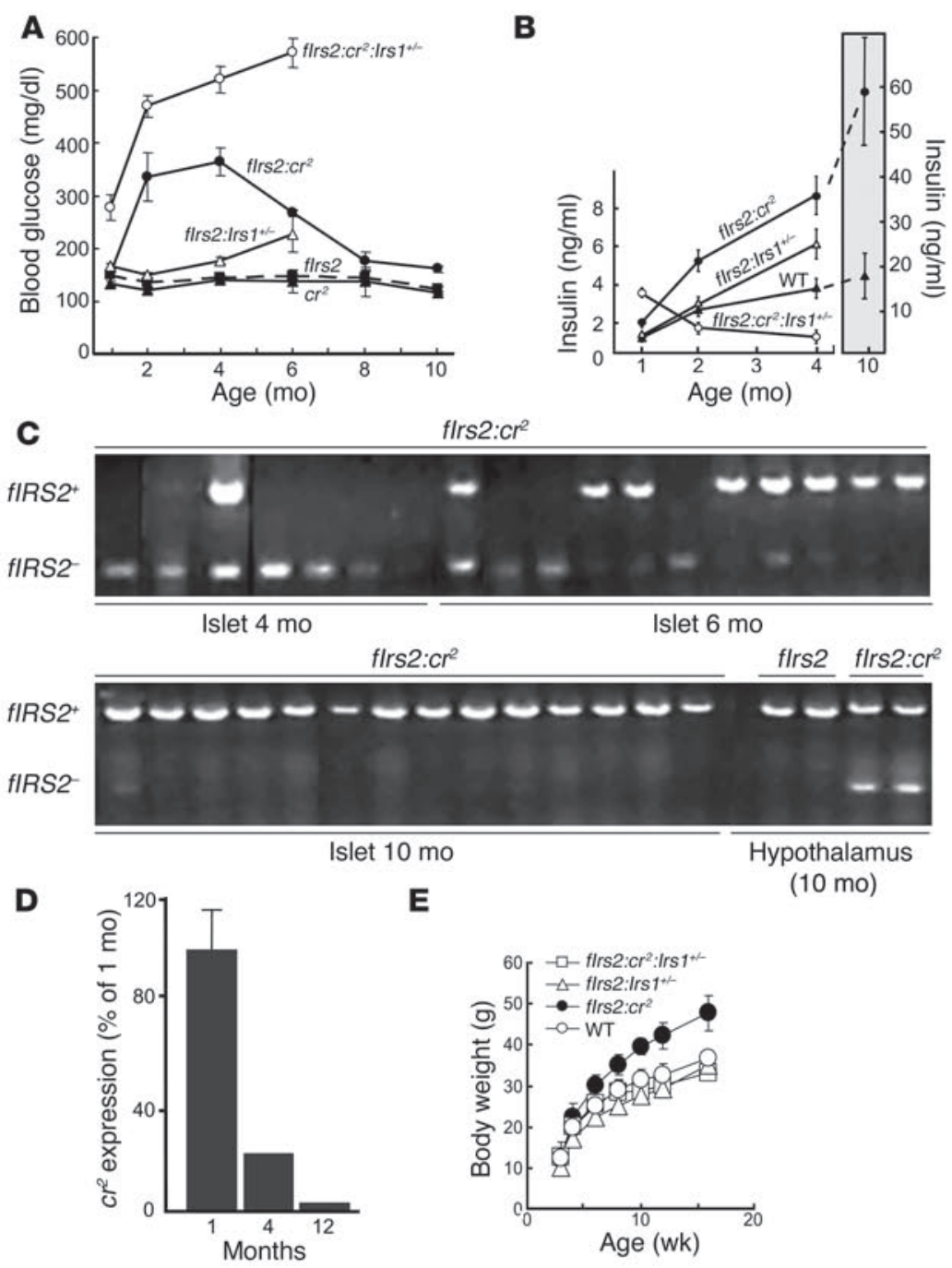

flrs2: $\mathrm{Cr}^{2}$

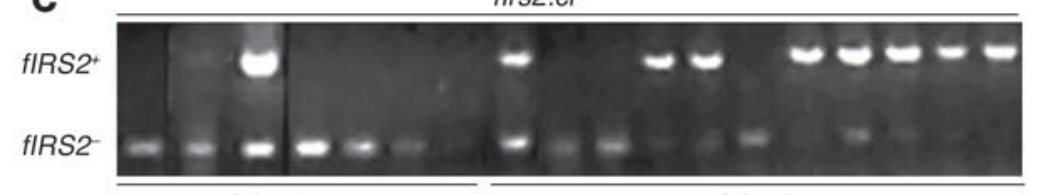

$\mathbf{F}$

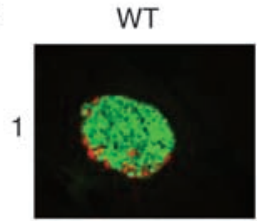

flrs2: $\mathrm{Cr}^{2}:$ Irs $1^{+/-}$
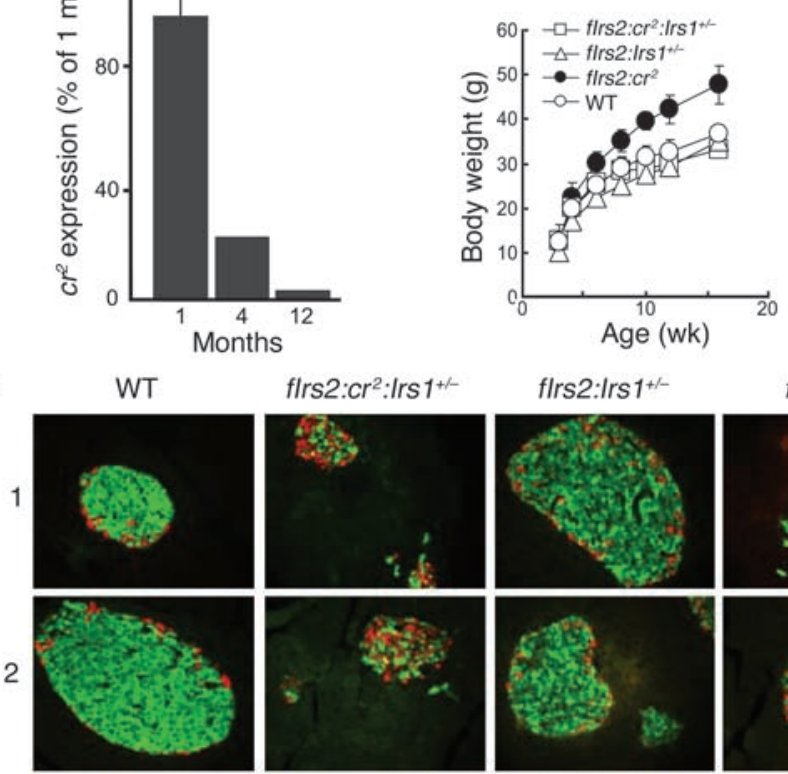

flrs2 flrs2: $\mathrm{Cr}^{2}$
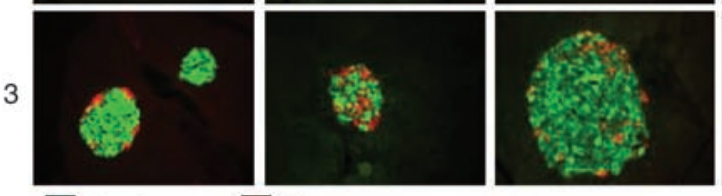

Glucagon

\section{Figure 4}

Pancreas $\beta$ cell function in aged fIrs2: $c r^{2}$ and flrs $2: c r^{2}$ : Irs $1^{+/-}$mice.(A) Random-fed blood glucose levels were determined at the indicated ages. Averages \pm SE were determined from at least 5 male mice per genotype. (B) Random insulin levels were determined in male mice of the indicated genotypes and ages. Averages \pm SE were determined from at least 5 mice per genotype. (C) Cremediated recombination/deletion of fIrs2 alleles was determined by real-time PCR analysis in single islets isolated from male flrs2: $\mathrm{Cr}^{2}$ mice at the indicated ages; or determined in hypothalamus from 10-month-old flrs2 or flrs2: $\mathrm{Cr}^{2}$ mice. (D) Real-time PCR analysis of $c r^{2}$ expression in isolated fIrs2: $c r^{2}$ islets at the indicated ages; mRNA levels were normalized against cyclophilin expression, and the averages \pm SE were determined for 2 male mice at each age. (E) Body weight of male littermates of the indicated genotypes that were fed regular chow and weighed weekly from postnatal day 21 until 16 weeks of age; each point represents the average \pm SE of at least 6 mice. $(F)$ Three representative pancreatic sections obtained from 6-month-old mice of the indicated genotypes immunostained with antibodies against insulin (green) or glucagon (red).

stimulated Akt phosphorylation was decreased in fIrs 2: $\mathrm{cr}{ }^{2}$ hypothalamic extracts (Figure 5A). These results confirmed that insulin signaling was reduced in fIrs $2: c r^{2}$ hypothalamus. By comparison, leptin-stimulated Stat3 or Akt phosphorylation were not significantly changed in fIrs $2: \mathrm{cr}^{2}$ mice (data not shown).

Food intake and insulin secretion increases $\alpha M S H$ secretion from POMC neurons in the hypothalamus, which stimulate MC4R signaling that promotes satiety (35). Our results were consistent with characteristics of reduced MC4R signaling, including excess appetite: Pomc1 mRNA levels - measured on Affymetrix GeneChip Mouse Expression Array 430A - were reduced almost 2 -fold (90\% confidence) in the hypothalamus of 16-hour-starved fIrs2: $c r^{2}$ mice (Figure 5B). Other neuropeptide mRNAs - neuropeptide Y (Npy), agouti-related protein (Agrp), and cocaine and amphetamine regulated transcript (Cart) - were not changed; and the mRNA levels encoding Stat3, suppressor of cytokine signaling 3 (Socs3), and pro-protein convertase- 2 - which processes $\alpha \mathrm{MSH}$ - were normal (Figure 5B).

Since $\alpha \mathrm{MSH}$ is a product of the POMC transcript in the arcuate nucleus, we immunostained hypothalamic sections from 8-week-old WT or fIrs $2: \mathrm{cr}^{2}$ mice with antibodies against Irs 2 or $\alpha \mathrm{MSH}$ (Figure $5 \mathrm{C})$. The size of the hypothalamus appeared normal. In WT mice, Irs 2 and $\alpha \mathrm{MSH}$ were coexpressed

minutes after intravenous insulin or saline injections. Irs 2 protein levels and tyrosine phosphorylation were reduced 30\% in fIrs $2: \mathrm{cr}^{2}$ extracts in comparison with WT, whereas levels of signal transducer and activator of transcription 3 (Stat3) protein - measured as a control - were equal in both mice (Figure 5A). Moreover, less $\mathrm{p} 85 \alpha / \beta$ was detected in Irs 2 immunoprecipitates, and insulin-
- as indicated by the yellow staining - in many but not all of the neurons near the 3 rd ventricle; however, yellow staining was absent in the fIrs $2: \mathrm{cr}^{2}$ sections, which suggested that many $\alpha \mathrm{MSH}$ neurons no longer expressed Irs2. These results show that some POMC neurons in the arcuate nucleus of fIrs $2: \mathrm{cr}^{2}$ mice were uncoupled from Irs2 signaling. 

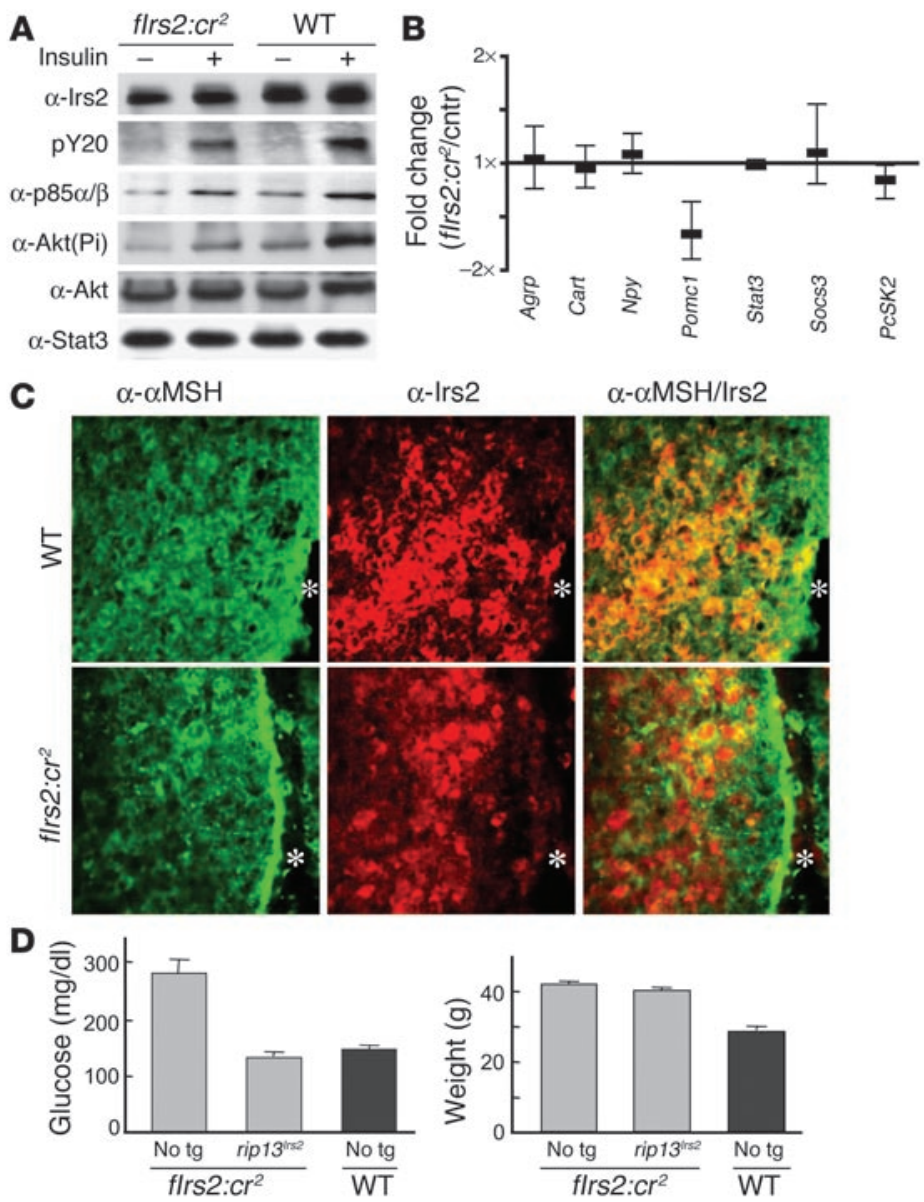

$\alpha-$ Irs2
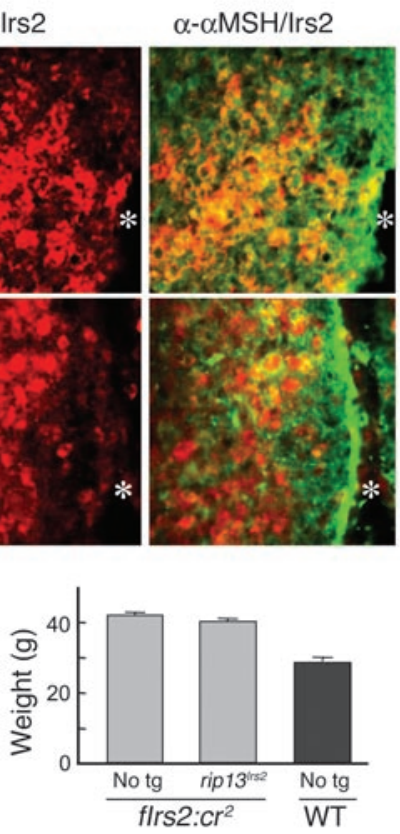

\section{Figure 5}

Analysis of hypothalamic function in the $f / r s 2: \mathrm{Cr}^{2}$ mice. (A) Immunoblots of hypothalamus lysates. After an overnight fasting, anesthetized 8-week-old mice were injected intravenously with $50 \mu \mathrm{l}$ of saline or saline containing 5 units of insulin. Fifteen minutes later, the hypothalamus was isolated and lysed. Lysates were immunoprecipitated with anti-Irs2 antibody, resolved by SDS-PAGE, and then immunoblotted with antibodies against Irs2, phosphotyrosine (pY20), or p85. Lysates were also blotted independently with antibodies against Akt or phospho-Akt [Akt(Pi)], or Stat3. Data are representative of at least three independent experiments. (B) The relative expression of various mRNAs—Npy (1421690_s_at), Agrp (1419127_at), Cart (1422825_at) or Pomc1 (1455858_x_at; 1433800_a_at), Stat3 (1426587_a_at; 1426587_a_at; 1460700_at), Socs3 (1455899_ x_at; 1456212_x_at) or PcSK2 (1448312_at; 1444147_at) was determined in hypothalamic extracts using Affymetrix GeneChip Mouse Expression Array 430A. The fold change is shown with the $90 \%$ confidence interval for expression in $3 \mathrm{flrs} 2: \mathrm{Cr}^{2}$ mice compared with the average control values from two WT, $2 \mathrm{cr}^{2}$ and 2 flrs 2 mice. Where more than one probe occurs on the Genechip, the average is reported. Cntr, control. (C) Brain sections from WT or fIrs2: $\mathrm{Cr}^{2}$ mice were immunostained with antibodies against $\alpha \mathrm{MSH}$ (green) or Irs2 (red). Yellow appears in the digitally merged images where $\alpha \mathrm{MSH}$ and Irs2 are coexpressed. Magnification, $\times 20$; ${ }^{*} 3$ rd ventricle. (D) Body weight and blood glucose levels of fIrs2: $c r^{2}$, [fIrs2: $\left.c r^{2}\right]: r i p 13^{l / s 2}$, and WT male mice at 8 weeks; average \pm SE was determined from 5 animals of each genotype. No tg, no transgene.
To confirm that weight gained by the fIrs $2: \mathrm{cr}^{2}$ mice during the first 8 weeks of life was due to dysregulated Irs 2 signaling in the CNS and not $\beta$ cell failure, we restored $\beta$ cell function by introducing transgenic Irs 2 into the $\beta$ cells of fIrs $2: c r^{2}$ mice. This was accomplished through an intercross with rip13 Irs 2 mice, which express recombinant Irs 2 in the $\beta$ cells but not in the hypothalamus (9). Hyperglycemia did not occur in the [fIrs 2:cr $\left.{ }^{2}\right]:$ rip $13^{\text {Irs } 2}$ mice; however, the mice continued to gain excess weight (Figure $5 \mathrm{D})$. Thus, partially dysregulated Irs2 signaling in the brain, rather than in $\beta$ cells, appears to be responsible for hyperphagia and obesity in the fIrs $2: \mathrm{cr}^{2}$ mice.

\section{Discussion}

Our results show that partial dysregulation of Irs 2 signaling in $\beta$ cells and brain - including the hypothalamus - may explain the close association between obesity, peripheral insulin resistance, and $\beta$ cell failure that characterizes type 2 diabetes. Whether dysregulation of IRS2 signaling contributes to type 2 diabetes and obesity in humans is unknown. However, allelic variations at the human IRS2 locus appear to be linked to obesity, glucose intolerance, and polycystic ovarian syndrome (36-38). Moreover, IRS1 and IRS2 functions are strongly inhibited by many heterologous signals, especially proinflammatory cytokines produced during acute trauma or chronic metabolic stress (5). Moreover, IRS2 expression is strongly induced by the cAMP response element binding protein (CREB), which is activated by cAMP agonists, including glucagon-like peptide 1 (GLP1) in $\beta$ cells (10). Dysregulation of
GLP1 signaling has been reported in type 2 diabetes, which might impair IRS2 expression in $\beta$ cells and the brain $(39,40)$.

Male fIrs2: $\mathrm{cr}^{2}$ mice develop diabetes between 2 and 3 months of age, at least in part because $\beta$ cells fail to compensate for peripheral insulin resistance. Unlike systemic Irs2 $2^{-/-}$mice that develop life-threatening diabetes earlier in life owing to complete loss of $\beta$ cells, the fIrs2:cr mice survive with diabetes until $\beta$ cell regeneration repopulates the islets with functional $\beta$ cells that cure diabetes. In fIrs $2: c r^{2}$ mice, the new $\beta$ cells must arise from cells that never expressed Cre. The progressive decline of Cre recombinase in islets is consistent with this mechanism. Inactivation of $c r^{2}$ by hyperglycemia - as shown for the insulin-2 gene itself-might explain the progressive loss of Cre that prevented deletion of fIrs 2 alleles in the new $\beta$ cells (41); however, more work is need to understand the exact mechanism involved.

New $\beta$ cells are thought to arise by division of $\beta$ cells themselves; by differentiation of islet precursors residing in pancreatic duct epithelium; or from bone marrow (42). Direct lineage tracing in adult mice suggests that terminally differentiated $\beta$ cells retain a significant proliferative capacity in vivo and are an important and possibly the only - source of new $\beta$ cells in adult mice (42). If $\beta$ cells that never express Cre recombinase are the sole source of islet regeneration in the fIrs $2: \mathrm{cr}^{2}$ mouse, the regenerative capacity must be significant. Intact fIrs 2 is barely detected in pooled islets at 2 months of age, which is consistent with previous reports showing that $c r^{2}$ mediates nearly complete deletion of floxed genes in $\beta$ cells $(32,43,44)$. At least a portion of the weak PCR signal revealing 
intact fIrs 2 in these islets arises from non- $\beta$ cells. Thus, $\beta$ cells in fIrs $2: c r^{2}$ islets that retain Irs 2 expression represent a distinct minority. Regardless of the source of regenerated $\beta$ cells, IRS2 signaling must play an important role in the process.

By contrast, systemic deletion of one Irs 1 allele from fIrs $2: c r^{2}$ mice caused early-onset diabetes and impaired $\beta$ cell regeneration. This result is unexpected, because Irs 1 plays a limited role in islet growth (34). The absence of 1 Irs 1 allele should not inhibit regeneration if the new $\beta$ cells arise by replication of a few $\beta$ cells that contain intact fIrs2. It remains possible that Irs1-dependent precursors contributed to the expansion of $\beta$ cell mass in the fIrs $2: c r^{2}$ mice. Alternatively, Irs 1 signaling might sustain the function of Irs2-deficieint $\beta$ cells long enough to permit the few Irs 2 -containing $\beta$ cells an opportunity to undergo division and repopulate the islets.

Diabetes is averted by the expression of transgenic Irs 2 in the fIrs 2 : $c r^{2} \beta$ cells, which suggests that strategies to promote Irs 2 expression may prevent or cure type 2 diabetes. Irs $2 \mathrm{mRNA}$ and Irs 2 protein is strongly upregulated in $\beta$ cells by cAMP $\rightarrow$ CREB signaling (10). A relevant example of this mechanism is the increased expression of IRS2 during activation of the GLP1 receptor by GLP1 itself or the long-acting homolog exendin-4 $(9,10)$. Improved insulin secretion, increased insulin sensitivity, and better appetite regulation reported in diabetic rodents and people treated with GLP1 or exendin- 4 can be explained by increased expression of IRS2 $(5,45)$. Since Irs 2 function is inhibited by serine phosphorylation and ubiquitin-mediated degradation that is mediated by proinflammatory cytokines (46), increased IRS2 expression together with effective management of chronic inflammation might prevent the progression of insulin resistance to diabetes.

The mild disruption of fIrs 2 by the $c r^{2}$ in the hypothalamus displays the features of dysregulated melanocortin signaling - increased appetite, lean and fat body mass, linear growth, and peripheral insulin resistance (15). Although obesity is usually thought to contribute directly to peripheral insulin resistance, lean fIrs $2: \mathrm{cr}^{2}$ mice were also relatively insulin resistant, hyperinsulinemic, and glucose intolerant compared with the control mice. The results from the hyperinsulinemic clamp suggest that the insulin resistance in the fIrs2: $\mathrm{cr}{ }^{2}$ mice resides in extra hepatic tissues - most likely the skeletal muscle - as hepatic glucose output is regulated normally by insulin, whereas glucose disposal is impaired. Previous work shows that dysregulated melanocortin signaling causes peripheral insulin resistance even before obesity develops, possibly because activation of MC4Rs in the paraventricular nucleus promotes peripheral insulin action $(47,48)$. The reduced levels of Pomc1 mRNA in fIrs $2: \mathrm{cr}^{2}$ hypothalamus and the loss of Irs 2 from neurons that express $\alpha \mathrm{MSH}$ reveal a potential mechanism for these effects. Thus, dysregulated Irs 2 signaling in the brain, especially the hypothalamus, could contribute to central and peripheral insulin resistance that predisposes individuals to obesity and diabetes (25).

The deletion of floxed insulin or Igf1 receptors by $\mathrm{cr}^{2}$ expression does not alter food intake or body weight $(43,49)$. If more careful analysis reveals the deletion of these receptor genes in the hypothalamus - as reported here for fIrs 2 and elsewhere for floxed Stat3 (32) - then loss of insulin or Igf1 receptor signaling might not promote obesity. This potential result would be similar to that obtained using the phenotype of neuron-specific insulin receptor $\mathrm{KO}$ (NIRKO) mice; only when placed on a diet containing $60 \%$ fat do NIRKO mice develop obesity.

Our work shows that Irs 2 signaling is important for $\beta$ cell growth, function, and survival. Moreover, our experiments show that $\beta$ cell regeneration in middle age can cure diabetes in mice and that Irs 2 signaling provides a significant advantage for this regeneration. Now we must determine whether the new $\beta$ cells arise from the division of a few preexisting $\beta$ cells that escaped fIrs 2 deletion or from non $-\beta$ cell precursors that never express Cre recombinase when they differentiate at middle age. Independent of the mechanism, strategies to enhance the Irs2 branch of the insulin/IGF-signaling pathway in $\beta$ cells and hypothalamus could be a rational approach to prevent obesity and diabetes.

\section{Methods}

Targeting vector and generation of mice. All methods discussed in this section involving animals have been approved by the Institutional Animal Care and Use Committee (IACUC) of Children's Hospital Boston, and by the Harvard School of Public Health review board. Irs2 genomic sequence was isolated from a 129 mouse genomic library as previously described (6). Two fragments of Irs 2 gene were cloned into a pPNT backbone vector that contained a neomycin selection cassette flanked by LoxP sites (Figure 1A). A 2.3-kb $5^{\prime} \mathrm{NheI} / \mathrm{Mscl}$ fragment was inserted in front of the neo cassette, and an 8 -kb MscI/Sall fragment - including a 200-bp 5'-untranslated region, 4-kb full-length coding sequence and the $3.8-\mathrm{kb} 3$ ' region - was cloned from the neo cassette. The latter sequence contains the third LoxP site located 60-bp downstream from the stop codon. The linearized targeting vector was transfected into male R1 embryonic stem cells derived from 129 mouse strain (51). Double selection was performed with G418 and ganciclovir, and drug-resistant clones were screened for homologous recombination by Southern blotting. Recombinants were subject to transfection by a Cre-containing plasmid, and clones maintaining flrs 2 but losing the neo cassette were selected by Southern analysis and injected into blastocysts from C57BL/6 mice. Chimeric male pups were bred with C57BL/ 6 females to confirm germ-line transmission.

$c r^{2}$ mice were purchased from The Jackson Laboratory and maintained in a heterozygous state. Generation of Irs1 KO mice and rip13 ${ }^{\text {Irs2 }}$ transgenic mice was as previously described $(6,9)$. To generate fIrs2: $\mathrm{cr}^{2}$ mice (mice homozygous for the fIrs 2 allele and carrying $c r^{2}$ transgene), we bred heterozygous flrs 2 with $c r^{2}$ first, and then mice double heterozygous for fIrs 2 and $c r^{2}$ were mated with flrs 2 heterozygous mice to obtain flrs $2: \mathrm{cr}^{2}$ and control mice (homozygous for the fIrs2 allele, $c r^{2}$ transgenic, and WT). To generate fIrs2:cr ${ }^{2}: I r s 1^{+/-}$and fIrs2:cr2:rip13 Irs2 mice, fIrs2:cr ${ }^{2}$ females were bred with fIrs2:Irs $1^{+/-}$and fIrs2: rip $13^{I r s 2}$ males, respectively. All mice were maintained on a mixed C57BL/6 $\times 129$ Sv genetic background, housed in a pathogen-free environment in a 12-hour light/dark cycle facility, and fed a normal (9\%) or low-fat (5\%) diet (Research Diet). Routine genotyping was performed on tail DNA by PCR. Primers for fIrs2 allele were 5'-ACTTGAAGGAAGCCACAGTCG and 3'-GTCCACTTTCCTGACAAGC. They flanked the last LoxP site and amplified a 200-bp product in WT allele and a 240-bp product in fIrs 2 allele. Genotyping for Irs1, rip1 $13^{I r s 2}$, and $c r^{2}$ mice has been described $(6,9,43)$.

Assessment of recombination. Mice were anesthetized with sodium amobarbital $\left(100 \mathrm{mg} \mathrm{kg}^{-1}\right)$. Islets were isolated by intraductal collagenase digestion (13). Various tissues were collected for genomic DNA extraction. Recombination was assessed by PCR analysis using two $5^{\prime}$ and one $3^{\prime}$ primers. The first $5^{\prime}$ primer, TCCGATCATATTCAATAACCCTTA, which included part of the first LoxP sequence, paired with the 3 '-primer, TACACTGAGACAGAAGGTTAGG, which was located downstream of the last LoxP site, to give rise to a 250 -bp recombined product. The other 5 ' primer, ACGTCGTCGCCACAGTTCAGAG, in the coding region of Irs2, paired with the same 3' primer to amplify a 750-bp un-recombined fIrs 2 product.

Metabolic analysis. Body weight was measured weekly beginning on postnatal day 21. Food intake during 24 hours was determined using the Comprehensive Lab Animal Monitoring System (Columbus Instru- 
ments). Lean and fat body mass were determined by dual-energy $\mathrm{x}$-ray absorptiometry (52). Carcasses were digested by alcoholic potassium hydroxide hydrolysis at $60^{\circ} \mathrm{C}$ overnight, and body lipid was determined as described previously (53).

Glucose and insulin levels and the various tolerance tests were performed upon fasted mice (16-hour overnight fast) or random-fed mice (test conducted in the morning between 9:00 and 11:00 without an overnight fast). Glucose levels were measured in mouse-tail blood using a Glucometer Elite (Bayer), and glucose tolerance tests were performed on mice after a 16-hour overnight fast (6). Blood insulin and leptin levels were determined from tail bleeds using a Rat Insulin ELISA kit and Mouse Leptin ELISA kit (Crystal Chem Inc.) (9).

Euglycemic hyperinsulinemic clamp. Euglycemic hyperinsulinemic clamp was performed on fasted conscious mice as previously described (54). $\left[3-{ }^{3} \mathrm{H}\right]$ glucose (NEN) was continuously infused during a 4-hour period at the rate of $0.05 \mu \mathrm{Ci} / \mathrm{min}$. Basal hepatic glucose output was measured in blood collected at 100 and 120 minutes after initiation of the $\left[3-{ }^{3} \mathrm{H}\right]$ glucose infusion. Then a primed continuous infusion of human regular insulin (Humulin; Eli Lilly and Co.) was initiated at a rate of $20 \mathrm{pmol} \times \mathrm{kg}^{-1}$ $\times \mathrm{min}^{-1}$ to raise plasma insulin concentration to approximately $1100 \mathrm{pM}$. Glucose (20\%) was infused at variable rates as needed to clamp glucose levels at about $6 \mathrm{mM}$. While blood glucose levels were steady between 200 and 240 minutes, the rate of glucose production was determining by measuring every 10 minutes the blood levels of $\left[3-{ }^{3} \mathrm{H}\right]$ glucose and ${ }^{3} \mathrm{H}_{2} \mathrm{O}$. Clamped hepatic glucose output was calculated by subtracting glucose infusion rates from the rates of glucose appearance. Whole-body glucose disposal was expressed in terms of $\mathrm{mg}$ of glucose per kg of body weight per minute required to maintain euglycemia during hyperinsulinemia (54).

$m R N A$ quantitation by real-time PCR analysis. Total RNA was extracted from isolated, hand-picked islets using RNAqueous-4PCR kit (Ambion Inc.), and reverse transcribed using RETROscript kit (Ambion Inc.). Real-time PCR was performed on iCycler (Bio-Rad Laboratories). Primers and fluorescence-labeled probes for $H n f 4 \alpha$ were $5^{\prime}$ : ACGTGCTGCTCCTAGGCAAT, 3': TCGAGGATGCGGATGGA, probe: CACACGGCTCATCTCCGCTAGCTCTG; for $H n f 3 \beta 5^{\prime}$ : GAACTCCATCCGCCACTCTCT, 3': GCCCTTGCCAGGCTTGT, probe: TCAACGACTGCTTTCTCAAGGTGCCC; for $P d x 1,5^{\prime}$ : AGGAAAACAAGAGGACCCGTACT, 3': CGGGAGATGTATTTGTTAAATAAGAATTC, probe: CCTACACCCGGGCGCAGCTG; for Glut2, 5': TCTTCACGGATGCCAATTACC, 3': AGAACTGCTGGGCCATGTG, probe: AGCCCATCCTCGTGGCGCTG; for $c r^{2}, 5^{\prime}$ : TGGCCTGGTCTGGACACA, 3': CCAGGTTACGGATATAGTTCATGACA, probe: TGTCCGGTATTGAAACTCCAGCGCG; for Irs2, 5': GCGGCCTCATCTTCTTCACT, 3': AACTGAAGTCCAGGTTCATATAGTCAGA, probe: CGACAGCCGGCAGCGCTCTC; for cyclophilin, 5': CAGACGCCACTGTCGCTTT, 3': TGTCTTTGGAACTTTGTCTGCAA, probe: CCTACACCCGGGCGCAGCTG. The expression of cyclophilin was used to normalize RNA content. Each reaction was carried out in triplicate.

Immunoprecipitation and Western blotting. After an overnight (15- to 17hour) fast, mice were anesthetized before an insulin (5 units regular human insulin) or saline injection into the inferior vena cava. Fifteen minutes after injection, hypothalamus was removed and homogenized. Clarified supernatants containing $400 \mu \mathrm{g}$ of total protein were immunoprecipitated with anti-Irs2 antibody as described (6). Immunoblots were probed with antiIrs2 antibody to reveal Irs2 expression levels, with anti-phosphotyrosine antibody (pY20; Transduction Laboratories) to reveal insulin-stimulated Irs2 phosphorylation, and with anti-p85 $\alpha / \beta$ antibody to reveal PI3K activation in an indirect manner. To assess insulin-stimulated Akt activation, $50 \mu \mathrm{g}$ of supernatants was separated by SDS-PAGE and transferred to nitrocellulose. Membranes were probed with phospho-specific anti-Akt antibody (Cell Signaling Technology). The same membranes were stripped and re-probed with anti-Akt antibody (Cell Signaling Technology) to reveal Akt expression levels. Membranes were probed with anti-Stat3 antibody (Cell Signaling Technology) to serve as a protein loading control. The antibodies were detected by enhanced chemiluminescence (Calbiochem) and quantified using ImageQuant software (Amersham Biosciences).

Immunohistochemistry and morphometric analysis. Pancreata were removed from mice, cleared of fat and lymph nodes, fixed overnight in $4 \%$ paraformaldehyde, and embedded in paraffin. Sections $(5 \mu \mathrm{m}$ in thickness) were stained with anti-insulin antibody (Jackson ImmunoResearch Laboratories Inc.). $\beta$ Cell area was presented as percentage of the total surveyed pancreatic area occupied by $\beta$ cells and determined by point-counting morphometry as previously described (6). Briefly, sections were viewed using a Zeiss Axiovert S100 TV (Carl Zeiss) microscope at a magnification of $\times 10$. The islet cross-sectional area and total pancreatic area were measured using Openlab Image analysis software (version 3.14; Improvision). $\beta$ Cell mass was calculated by multiplying $\beta$ cell area by pancreatic weight. $\beta$ Cell size was determined by dividing $\beta$ cell area by $\beta$ cell number. $\beta$ Cell proliferation was determined by BrdU incorporation $(100 \mu \mathrm{g} / \mathrm{g}$ body weight; Roche Molecular Biochemicals) was injected intraperitoneally 6 hours before pancreas was collected. Double immunostaining for insulin and BrdU (Roche Molecular Biochemicals) was performed on pancreas sections. To distinguish between large ( $>10 \beta$ cells) and small ( $<10 \beta$ cells) islets, 1 entire section of pancreas immunostained by insulin - from 3 or 4 mice as indicated - was examined. For immunostaining of brain sections, mice were perfused with $10 \%$ formalin, and then whole brain was sliced with Microtome (American Optical Company). Thirty- $\mu$ m-thick sections were stained with antibodies against Irs2 (UBI), Cre (Covance), or $\alpha M S H$ (Chemicon). Grayscale images were normalized using ImageJ software, aligned using the Turbo Registration plug-in to ImageJ, then recolored as shown in the figures (55).

Microarray analysis. After an overnight fast, the hypothalamus was collected from 2 WT, 2 fIrs 2, $2 c r^{2}$ mice, and 3 fIrs2: $c r^{2}$ 8-week-old mice. Total RNA was extracted and purified from each sample using RNAqueous4PCR Kit (Ambion Inc.). cDNA synthesis and in vitro transcription was carried out using SuperScript Choice System (Invitrogen) and MEGAscript $\mathrm{T} 7 \mathrm{Kit}$ (Ambion Inc.) according to the manufacturers' instructions. Labeled probes were prepared by in vitro transcription using second-cycle cDNA synthesis products, and the samples were hybridized to Affymetrix GeneChip Mouse Expression Array 430A in a GeneChip Fluidics Station 400 and scanned with a Hewlett-Packard GeneArray Scanner (56). The data files (dat format) were normalized to the median array using dCHIP software (version 1.31), and the expression levels were calculated using the perfect match-only model (57). All of the reported genes were flagged as present by both Affymetrix GeneChip (version 5.0) and dCHIP. The fold change and the $90 \%$ confidence interval were calculated for average fIrs $2: \mathrm{cr}^{2}$ samples $(n=3)$ against the average control samples $(n=6)$.

\section{Acknowledgments}

This work was supported by NIH grant DK55236. X. Lin was a Juvenile Diabetes Foundation (JDF) postdoctoral fellow while this work was conducted.

Received for publication May 20, 2004, and accepted in revised form July 20, 2004.

Address correspondence to: Morris F. White, Howard Hughes Medical Institute Children's Hospital, Division of Endocrinology, Harvard Medical School, Karp Research Building, Room 04210, 300 Longwood Avenue, Boston, Massachusetts 02115, USA. Phone: (617) 919-2846; E-mail: morris.white@childrens.harvard.edu. 
1. Zimmet, P., Alberti, K.G., and Shaw, J. 2001. Global and societal implications of the diabetes epidemic. Nature. 414:782-787.

2. Diamond, J. 2003. The double puzzle of diabetes. Nature. 423:599-602.

3. DeFronzo, R.A. 1988. Lilly lecture 1987. The triumvirate: beta-cell, muscle, liver. A collusion responsible for NIDDM [review]. Diabetes. 37:667-687.

4. Shulman, G.I. 2000. Cellular mechanisms of insulin resistance. J. Clin. Invest. 106:171-176.

5. White, M.F. 2003. Insulin signaling in health and disease. Science. 302:1710-1711.

6. Withers, D.J., et al. 1998. Disruption of IRS-2 causes type 2 diabetes in mice. Nature. 391:900-904.

7. Kubota, N., et al. 2000. Disruption of insulin receptor substrate 2 causes type 2 diabetes because of liver insulin resistance and lack of compensatory beta-cell hyperplasia. Diabetes. 49:1880-1889.

8. Previs, S.F., Withers, D.J., Ren, J.M., White, M.F., and Shulman, G.I. 2000. Contrasting effects of IRS-1 vs IRS-2 gene disruption on carbohydrate and lipid metabolism in vivo. J. Biol. Chem. 275:38990-38994.

9. Hennige, A.M., et al. 2003. Upregulation of insulin receptor substrate- 2 in pancreatic $\beta$ cells prevents diabetes. J. Clin. Invest. 112:1521-1532. doi:10.1172/ JCI200318581.

10. Jhala, U.S., et al. 2003. cAMP promotes pancreatic beta-cell survival via CREB-mediated induction of IRS2. Genes Dev. 17:1575-1580.

11. Kushner, J.A., et al. 2004. Islet-sparing effects of protein tyrosine phosphatase- $1 \mathrm{~b}$ deficiency delays onset of diabetes in IRS2 knockout mice. Diabetes. 53:61-66.

12. Kitamura, T., et al. 2002. The forkhead transcription factor Foxo1 links insulin signaling to $P d x 1$ regulation of pancreatic $\beta$ cell growth. J. Clin. Invest. 110:1839-1847. doi:10.1172/JCI200216857.

13. Kushner, J.A., et al. 2002. Pdx1 restores $\beta$ cell function in Irs2 knockout mice. J. Clin. Invest. 109:1193-1201. doi:10.1172/JCI200214439.

14. Suzuki, R., et al. 2003. Pdx1 expression in Irs2-deficient mouse beta-cells is regulated in a strain-dependent manner. J. Biol. Chem. 278:43691-43698

15. Butler, A.A., and Cone, R.D. 2003. Knockout studies defining different roles for melanocortin receptors in energy homeostasis. Ann. N. Y. Acad. Sci. 994:240-245.

16. Farooqi, I.S., et al. 2003. Clinical spectrum of obesity and mutations in the melanocortin 4 receptor gene. N. Engl. J. Med. 348:1085-1095.

17. Schwartz, M.W., et al. 2000. Central nervous system control of food intake. Nature. 404:661-671.

18. Qi, Y., et al. 2004. Adiponectin acts in the brain to decrease body weight. Nat. Med. 10:524-529.

19. Myers, M.G.,Jr. 2004. Leptin receptor signaling and the regulation of mammalian physiology. Recent Prog. Horm. Res. 59:287-304

20. Woods, S.C., Lotter, E.C., McKay, L.D., and Porte, D., Jr. 1979. Chronic intracerebroventricular infusion of insulin reduces food intake and body weight of baboons. Nature. 282:503-505.

21. Schwartz, M., Figlewicz, D.P., Baskin, D.G., Woods, S.C., and Porte, D. 1992. Insulin in the brain: A hormonal regulator of energy balance. Endocr. Rev. 13:387-414.
22. Schwartz, M.W., Baskin, D.G., Kaiyala, K.J., and Woods, S.C. 1999. Model of the regulation of energy balance and adiposity by the central nervous system. Am. J. Clin. Nutr. 69:584-596.

23. Bruning, J.C., et al. 2000. Role of brain insulin receptor in control of body weight and reproduction. Science. 289:2122-2125.

24. Huszar, D., et al. 1997. Targeted disruption of the melanocortin-4 receptor results in obesity in mice. Cell. 88:131-141.

25. Obici, S., et al. 2001. Central melanocortin receptors regulate insulin action. J. Clin. Invest. 108:1079-1085. doi:10.1172/JCI200112954

26. Challis, B.G., et al. 2002. A missense mutation disrupting a dibasic prohormone processing site in pro-opiomelanocortin (POMC) increases susceptibility to early-onset obesity through a novel molecular mechanism. Hum. Mol. Genet. 11:1997-2004.

27. Yamauchi, T., et al. 2003. Cloning of adiponectin receptors that mediate antidiabetic metabolic effects. Nature. 423:762-769.

28. Combs, T.P., et al. 2003. Sexual differentiation, pregnancy, calorie restriction, and aging affect the adipocyte-specific secretory protein adiponectin. Diabetes. 52:268-276.

29. Spranger, J., et al. 2003. Adiponectin and protection against type 2 diabetes mellitus. Lancet. 361:226-228

30. Burks, D.J., et al. 2000. IRS-2 pathways integrate female reproduction and energy homeostasis. Nature. 407:377-382.

31. Gannon, M., Shiota, C., Postic, C., Wright, C.V., and Magnuson, M. 2000. Analysis of the Cre-mediated recombination driven by rat insulin promoter in embryonic and adult mouse pancreas. Genesis. 26:139-142.

32. Cui, Y., et al. 2004. Essential role of STAT3 in body weight and glucose homeostasis. Mol. Cell. Biol. 24:258-269.

33. Schubert, M., et al. 2003. Insulin receptor substrate-2 deficiency impairs brain growth and promotes tau phosphorylation. J. Neurosci. 23:7084-7092.

34. Withers, D.J., et al. 1999. Irs- 2 coordinates Igf-1 receptor-mediated beta-cell development and peripheral insulin signalling. Nat. Genet. 23:32-40.

35. Schwartz, M.W. 2001. Progress in the search for neuronal mechanisms coupling type 2 diabetes to obesity. J. Clin. Invest. 108:963-964. doi:10.1172/ JCI200114127.

36. Lautier, C., et al. 2003. Complex haplotypes of IRS2 gene are associated with severe obesity and reveal heterogeneity in the effect of Gly1057Asp mutation. Hum. Genet. 113:34-43.

37. Ehrmann, D.A., Tang, X., Yoshiuchi, I., Cox, N.J., and Bell, G.I. 2002. Relationship of insulin receptor substrate-1 and - 2 genotypes to phenotypic features of polycystic ovary syndrome. J. Clin. Endocrinol. Metab. 87:4297-4300.

38. Stefan, N., et al. 2004. The Gly1057Asp polymorphism in IRS- 2 interacts with obesity to affect beta cell function. Diabetologia. 47:759-761.

39. Brubaker, P.L., and Drucker, D.J. 2004. Glucagonlike peptides regulate cell proliferation and apoptosis in the pancreas, gut and central nervous system. Endocrinology. 145:2653-2659.

40. During, M.J., et al. 2003. Glucagon-like peptide-1 receptor is involved in learning and neuroprotec- tion. Nat. Med. 9:1173-1179.

41. Ling, Z., Heimberg, H., Foriers, A., Schuit, F., and Pipeleers, D. 1998. Differential expression of rat insulin I and II messenger ribonucleic acid after prolonged exposure of islet beta-cells to elevated glucose levels. Endocrinology. 139:491-495.

42. Dor, Y., Brown, J., Martinez, O.I., and Melton, D.A. 2004. Adult pancreatic beta-cells are formed by self-duplication rather than stem-cell differentiation. Nature, 429:41-46.

43. Kulkarni, R.N., et al. 1999. Tissue-specific knockout of the insulin receptor in pancreatic $\beta$ cells creates an insulin secretory defect similar to that in type 2 diabetes. Cell. 96:329-339.

44. Postic, C., et al. 1999. Dual roles for glucokinase in glucose homeostasis as determined by liver and pancreatc beta cell-specific gene knock-outs using Cre recombinase. J. Biol. Chem. 274:305-315.

45. Zander, M., Madsbad, S., Madsen, J.L., and Holst, J.J. 2002. Effect of 6-week course of glucagon-like peptide 1 on glycaemic control, insulin sensitivity, and beta-cell function in type 2 diabetes: a parallelgroup study. Lancet. 359:824-830.

46. Rui, L., Yuan, M., Frantz, D., Shoelson, S., and White, M.F. 2002. SOCS-1 and SOCS-3 block insulin signaling by ubiquitin-mediated degradation of IRS1 and IRS2. J. Biol. Chem. 277:42394-42398.

47. Shimomura, I., et al. 2000. Decreased IRS-2 and increased SREBP-1c lead to mixed insulin resistance and sensitivity in livers of lipodystrophic and ob/ob mice. Mol. Cell. 6:77-86.

48. Obici, S., Feng, Z., Karkanias, G., Baskin, D.G., and Rossetti, L. 2002. Decreasing hypothalamic insulin receptors causes hyperphagia and insulin resistance in rats. Nat. Neurosci. 5:566-572.

49. Kulkarni, R.N., et al. 2002. beta-cell-specific deletion of the Igf1 receptor leads to hyperinsulinemia and glucose intolerance but does not alter beta-cell mass. Nat. Genet. 31:111-115.

50. Niswender, K.D., et al. 2003. Insulin activation of phosphatidylinositol 3-kinase in the hypothalamic arcuate nucleus: a key mediator of insulin-induced anorexia. Diabetes. 52:227-231.

51. Wood, S.A., Allen, N.D., Rossant, J., Auerbach, A., and Nagy, A. 1993. Non-injection methods for the production of embryonic stem cell-embryo chimaeras. Nature. 365:87-89.

52. Nagy, T.R., and Clair, A.L. 2000. Precision and accuracy of dual-energy X-ray absorptiometry for determining in vivo body composition of mice. Obes. Res. 8:392-398.

53. Fredrich, R.C., et al. 1995. Leptin levels reflect body lipid content in mice: evidence for diet-induced resistance to leptin action. Nat. Med. 1:1311-1314.

54. Kim, J.K., et al. 2001. Tissue-specific overexpression of lipoprotein lipase causes tissuespecific insulin resistance. Proc. Natl. Acad. Sci. U. S. A. 98:7522-7527.

55. Thevenaz, P., Ruttimann, U.E., and Unser, M. 1998. A pyramid approach to subpixel registration based on intentisy. IEEE Trans. Image Process. 7:27-41.

56. MIT Biopolymers Laboratory. http://web.mit.edu/ biopolymers/www/.

57. Li, C., and Wong, W.H. 2001. Model-based analysis of oligonucleotide arrays: expression index computation and outlier detection. Proc. Natl. Acad. Sci. U. S. A. 98:31-36. 